\title{
3 Research Square

\section{Impact of nephron sparing surgery on survival in upper urinary tract urothelial carcinoma patients stratified by tumor characteristics}

Liang Jin

Shanghai Tenth People's Hospital https://orcid.org/0000-0002-4530-7597

Ting-shuai Zhai

Shanghai Tenth People's Hospital

Zhen Zhou

Nanjing Medical University

Xiang Liu

shanghai putuo district people's hospital of tongji university

Jia-xin Zhang

Shanghai Tenth People's Hospital

Xiao-cui Nie

Shenyang women and children's hospital

Hui-qing Liu

Center of Reproductive medicine of ji'an maternal and child health hospital

Xu-dong Yao

Shanghai Tenth People's Hospital

Feng Yue

Dalian friendship hospital

Lin Ye ( $D$ ericyelin@163.com )

Shanghai Tenth People's Hospital https://orcid.org/0000-0001-5377-2264

\section{Research article}

Keywords: upper urinary tract urothelial carcinoma, nephron sparing surgery, SEER, survival analysis

Posted Date: November 6th, 2020

DOl: https://doi.org/10.21203/rs.3.rs-20146/v2

License: (1) (1) This work is licensed under a Creative Commons Attribution 4.0 International License.

Read Full License 


\section{Abstract}

Background: We aimed to evaluate the impact of nephron sparing surgery (NSS) on survival in upper urinary tract urothelial carcinoma (UTUC) patients stratified by tumor grade and stage compared to radical nephroureterectomy (RNU) or no surgery.

Methods: Overall, 10319 UTUC patients between 2004 and 2015 were extracted from the SEER database. Patients were divided into no surgery group, NSS group and RNU group. Kaplan-Meier plots illustrated survival rates according to surgical method. Multivariable Cox regression analyses assessed the effect of different surgical methods on survival rates.

Result: Among the 10319 UTUC patients. Kaplan-Meier plots showed that NSS was associated with a higher overall survival (OS) and cancer-specific survival (CSS) in grade $\nabla$ and $\nabla$ and AJCC stage $\nabla$ patients

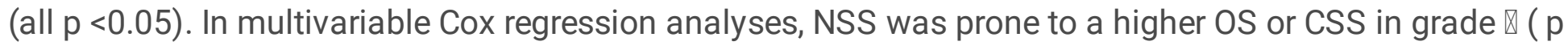
$>0.05)$. Moreover, NSS predisposed to a higher OS only in AJCC stage $\otimes(p<0.05)$.

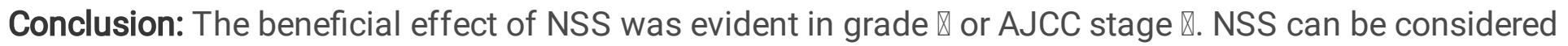
in grade $\Downarrow$ or stage $\otimes$, for other grades or stages remains to be seen, both of which will be verified by further prospective research.

\section{Background}

Urothelial carcinomas are the fourth most common tumor, most of which are located in the lower urinary tract and upper tract urothelial carcinoma (UTUC) accounts for only $5 \%$ of urothelial tumors and $8 \%$ of renal tumors ${ }^{[1,2]}$. Radical nephroureterectomy (RNU) with bladder cuff excision is the gold standard treatment for UTUC. However, solitary kidney after RNU may lead to higher risk of dialysis, cardiovascular morbidity and overall mortality ${ }^{[3,4]}$.In an effort to decrease the potential risk, nephron sparing surgery deserves attention greatly in elaborately chosen patients with UTUC with the intention of obtaining acceptable oncological results ${ }^{[5-7]}$.

Although the stage of UTUC is usually determined by endoscopic biopsy during ureteroscopy, inadequate tissue sampling and concerns about ureteral perforation make accurate staging challenging ${ }^{[8,9]}$. Therefore, due to concerns of cancer progression, many clinicians are willing to perform radical eradication therapy even in patients with early-stage UTUC ${ }^{[10,11]}$. However, some scholars have suggested that NSS may play a curative role especially in low grades and early stages ${ }^{[12,13]}$. Nevertheless, evidencebased data are scarce to support the oncologic efficacy of NSS for its rarity.

Originally, NSS was exclusively considered for UTUC patients who are intolerance of RNU or those with imperative indications such as anatomically or functionally solitary kidneys. Recently, It is that elective risk-based indications were introduced for patients with bilateral functional kidneys when obtaining effective oncologic control for these emergency cases ${ }^{[14]}$. As a result, all the contemporary reports comparing NSS versus RNU have included a mix of patients with imperative and elective indications, and 
the available data are therefore highly heterogeneous ${ }^{[15]}$, which makes it difficult to draw any reasonable conclusions from the current literature. To clarify this issue, we evaluated and compared the treatment of NSS on overall survival (OS) and cancer-specific survival (CSS) when compared to RNU or no surgery.

\section{Methods}

\section{Data source and patients}

Within the Surveillance, Epidemiology and End Results (SEER) database from 2004 to 2015, we used the National Cancer Institute's SEER*Stat software (version 8.3.5) with UTUC (codes C65.9 and C66.9) to identified 10,319 patients treated with NSS, RNU or no surgery between January 1, 2004, to December 31, 2015. The exclusion criteria were as follows: (a) unknown survival time; (b) unclear grade or AJCC stage; (c) patients under 18 years of age; (d) unclear tumor location; (e)surgical code is not 00, 30, 40, 50. Finally, 10,319 eligible patients were identified in the present research.

\section{Study variables}

Study variables included age of diagnosis, year of diagnosis, sex, race, marital status, urban-rural residence, insurance, summary AJCC stage, grade, surgical method, radiotherapy and chemotherapy information. According to the surgical code, patients were divided into three groups: no surgery (code 00, no cancer-directed surgery of primary site), NSS group (code 30, Partial or subtotal nephrectomy or partial ureterectomy, including Cryosurgery, Electrocautery, Excisional biopsy, Laser, Segmental resection, Thermal ablation, Wedge resection) and RNU group (code 40,50. Radical nephrectomy). AJCC stage is refer to AJCC Cancer Staging Manual, 7th Edition. Meanwhile these group are divided into four groups according to the 2016 WHO classification (grade I, grade II, grade III and grade IV). Demographic and clinicopathological characteristics including age at diagnosis (18-50, 51-65, 66-80 and >80), sex (male and female), race (white, black and others), marital status (married, unmarried and unknown), urban-rural residence (metropolitan and nonmetropolitan), summary stage (localized, regional, distant), radiotherapy (yes or no) and chemotherapy (yes or no). Household income was divided into three group: lower group (<4219), middle group (4219-5210) and upper group (>5210). OS and CSS are the primary endpoints of our study.

\section{Statistical analysis}

Statistical Package for the Social Sciences software (version 24.0; SPSS Inc, Chicago, IL, USA) was used for all statistical analyses. The chi-square test was used to analyze factors related to the surgical method. Kaplan-Meier curves analyses using a log-rank test was used to analyze the OS and CSS rate. Multivariate Cox regression was used to analyses factors associated with OS and CSS. P value $\leq 0.05$ was considered statistically significant.

\section{Results}




\section{General characteristics}

A total of 10,319 eligible UTUC patients were identified in our study cohort between 2004 and 2015. Among them, 963 (9.3\%) patients did not received surgery, 1,273 (12.3\%) received NSS and 8,083 (78.3\%) received RNU. Table 1 demonstrated the demographic and clinicopathological characteristics of patients with UTUC. Chi-square test showed some risks had an impact on therapeutic decision making.

Of the 10,319 patients, the proportion of NSS remained stable from 2004 to 2015, while the proportion of NSS decreased in pelvis patients (Figure 1).

\section{Survival related variables}

Kaplan-Meier curves analysis the influence of risk factors on OS and CSS of UTUC patients (Table 2). Patients undergoing NSS had the longest OS median survival time (MST) (70.00 months) and highest CSS MST (115.10 months) compared with the other groups.

\section{Survival analyses according to surgical method}

As shown in Table S1, the 3,5,10-year OS for the population who received NSS was significantly longer than RNU patients in WHO grade III ( $58.3 \%$ vs $50.3 \%, 46.5 \%$ vs $37.1 \%, 27.1 \%$ vs $22.8 \%, p<0.001)$. In addition, In the stage IV, NSS patients have longer survival ratio when compared with RNU patients (33.4 $\%$ vs $22.0 \%, 20.8 \%$ vs $14.9 \%, 16.3 \%$ vs $8.7 \%, p<0.001)$.

Multivariate cox regression analysis revealed some risk factors in UTUC patients (Table 3). After adjusting for risk factors, The results shown that compared with the patients who receive RNU treatment , no surgery patients (HR:3.78, 95\% Cl: 3.51-4.08, $p<0.001$ ) may be at increased risk. In term of CSS, no surgery patients (HR: $2.46,95 \% \mathrm{Cl}: 2.18-2.77, p<0.001)$ associated more commonly with low-risk CSS, while the people performed with NSS (HR: $0.78,95 \% \mathrm{Cl}: 0.67-0.91, p=0.002$ ) may also associated with significantly greatest odds of CSS.

\section{Subgroup analysis stratified by AJCC stage and WHO grade}

Based on summary stage and WHO grade, we further discussed the difference between surgical method and prognosis among the subgroups of patients (Table 4). We found that for OS and CSS, surgical method was still associated with them among different stage and various grade subgroups patients. Kaplan-Meier plots showed that NSS was associated with a higher overall survival (OS) and cancerspecific survival (CSS) in grade $\otimes$ and $\otimes$ and AJCC stage $\otimes$ patients (all $p<0.05$ ) (Figure 2, Figure 3 ). In multivariable COX regression analyses, NSS patients had a higher OS rate in stage IV group (OS: HR: 0.74, $95 \% \mathrm{Cl} 0.60-0.90, \mathrm{p}=0.003$ ) and a higher OS or CSS rate in grade III group compared to RNU patients. However, for other subgroup patients, the surgical method had no obvious effect in terms of $\mathrm{OS}$, as well as CSS $(p>0.05)$. When classified according to the primary organ, the related results are shown in the supplementary materials (Table S2-S3). Supplemental Figure 1-4 was performed to verify the NSS group was prone to a higher OS or CSS in the former periods. 


\section{Discussion}

Our study was based on a large number of population database to quantitatively compare the impact of NSS on survival in patients with UTUC compared to RNU or no surgery. UTUC is a rare disease with an annual incidence of one to two cases per 100000 individuals in Western countries. We explored the effect of surgical methods on OS and CSS in UTUC patients and discovery that surgical method was an independent prognostic factor. Moreover, the mean survival time was higher in NSS group than in RNU

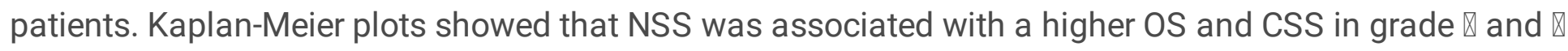
and AJCC stage $₫$ patients. In multivariable Cox regression analyses, NSS was prone to a higher OS or

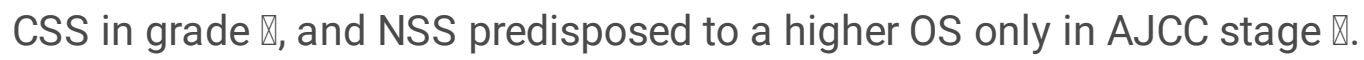

In our research, the OS and CSS of NSS and RNU were not significant for low-grade or early-stage with the selected UTUC patients. This result is similar to the previous report. Jay Simhan et al[16] reported that patients with similar situation when treated with NSS have analogous cancer-specific mortality (CSM) rates to those patients managed with RNU. Jeldres et al. ${ }^{[17]}$ thought segmental ureterectomy (SU) may be operated to UTUC patients when it is technically feasible, especially when detected in T3 or even T4 lesions. Moreover, Giovanni Lughezzani ${ }^{[18]}$ report a stage and grade migration at NU or SU towards more aggressive disease among surgically treated patients between 1983 and 2004. But the CSM rates are not higher than former that validates the two surgical ways as effective treatments for UTUC. However , In another research $₫$ Chen $\mathrm{GL}^{[12]}$ reported acceptable oncological outcomes were observed in 23 patients undergoing laser ablation with strict ureteroscopic surveillance. In another side, the use of NSS has become an acceptable alternative in select patients with non-high grade, early-stage UTUC who are at low risk of disease progression ${ }^{[19,20]}$, However, the risk of cancer progression or recurrence is estimated to be as high as $30 \%$ within 5 years $^{[21]}$. A large part of the difference in these results is due to competing model factors for the selected patient sample as well as aspects of the patient profile. In addition, radiotherapy is usually administered in symptomatic patients or patients unable to undergo radical surgery ${ }^{[22]}$, however, Li Xiaoying ${ }^{[23]}$ concluded radiotherapy can reduce local recurrence rate in patients with radical nephroureterectomy. In our research, we also found radiotherapy may benefit in UTUC patients. It may result from the population with surgery and high grade occupy most of the population, and radiotherapy may further improve the survival rate of patients. Meanwhile, there are studies focusing on the role of chemotherapy on survival for UTUC patients, and the therapeutic effects differ for different patients. In Zhai Ting-Shuai's research ${ }^{[24]}$, The beneficial effect of chemotherapy on survival probability was evident in pT3/pT4 or patients with lymph node metastasis, this may be involved more population with distant metastasis and more people are may have strong will of survival, so they have to face more treatment including receive extra chemotherapy. In other side, we observed that NSS has higher a OS or CSS when compared to RNU methods especially in Grade III and AJCC stage IV. In a multi cental research, Kaag et al. ${ }^{[25]}$ identified a reduction in mean estimated GFR by $\approx 24 \%$ after RNU in tumor patients. Thus, patients when operated with RNU have notable decreases in renal function and leading to chronic kidney disease ${ }^{[26]}$. Importantly, such a decline in renal function after radical surgery in patients with UTUC may affect eligibility in the event of disease progression ${ }^{[27]}$. We concerned more about NSS surgery because 
NSS could protect the nephron, and it could better maintain the life of the patient with solitary kidney, thereby prolonging the survival period. Previous studies examining the oncological efficacy in patients managed conservatively were limited by small sample sizes, lack of generalizability, and inclusion of patients with aggressive disease characteristics. Using national registry data, the present multicenter large-sample study might be more convincing.

There are limitations in our research. First, the SEER database is a retrospective dataset. Second, the patient's physical condition was unclear, patients with much complications might pursue more conservative treatment. Third, patients receiving NSS may have a selection bias relative to RNU. In addition, for chemotherapy and radiotherapy, we didn't distinguish whether adjuvant or neoadjuvant therapy, and there is no information on specific RT technique (dose, fractionation, beam energy) or chemotherapy regimens.

\section{Conclusions}

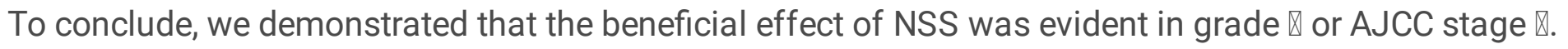
NSS can be considered in grade $\otimes$ or stage $\otimes$, for other grades or stages remains to be seen, both of which will be verified by further prospective research.

\section{Abbreviations}

NSS: nephron sparing surgery; UTUC: upper urinary tract urothelial carcinoma; RNU: radical nephroureterectomy; OS: overall survival; CSS: cancer-specific survival; SEER: the Surveillance, Epidemiology and End Results; MST: median survival time

\section{Declarations}

\section{Ethics approval and consent to participate}

For the institutional cohorts, data were extracted from the Surveillance, Epidemiology, and End Results database. This article does not contain any studies with human participants performed by any of the authors. For this type of study, formal consent is not required.

\section{Consent for publication}

Not applicable.

\section{Availability of data and material}

The datasets used and/or analyzed during this current study are available from the corresponding author on reasonable request. 
The authors declare that they have no competing interests.

\section{Funding}

This work was supported by grants from the National Natural Science Foundation of China (No.81672549 \& 81972409), Natural Science Foundation of Shanghai (No. 15ZR1433000), The sanitation system self-dependent innovation foundation of Putuo district in Shanghai (No. PTKWWS201819). The funding bodies had no role in the design of the study and collection, analysis, and interpretation of data and in writing the manuscript.

\section{Authors' contributions}

$\mathrm{L} \mathrm{J}$ contributed to study designation, data analysis, methodology, data validation and original draft writing. TS Z contributed to data collection, manuscript preparation and edition. Z Z contributed to data collection, formal analysis, investigation and visualization. $X \mathrm{~L}$ contributed to formal analysis, methodology and validation. JX Z contributed to formal analysis and methodology. XC N contributed to formal analysis and methodology. HQ L contributed to data collection. XD Y contributed to conceptualization and supervision. LM F contributed to conceptualization, supervision and editing. L Y contributed to conceptualization, funding acquisition, resources, supervision and writing-review and editing. All authors have read and approved the manuscript.

\section{Acknowledgements}

We would like to express our most sincere thanks to the technical assistance of the department of urology in shanghai tenth people' hospital and all the patients involved in SEER database.

\section{References}

[1]. Siegel RL, Miller KD, Jemal A: Cancer statistics, 2019. Ca-Cancer J Clin 2019, 69(1):7-34.

[2]. Froemming A, Potretzke T, Takahashi N, Kim B: Upper tract urothelial cancer. Eur J Radiol 2018, 98:5060 .

[3]. Zini L, Perrotte P, Capitanio U, Jeldres C, Shariat SF, Antebi E, Saad F, Patard JJ, Montorsi F, Karakiewicz PI: Radical versus partial nephrectomy: effect on overall and noncancer mortality. Cancer-Am Cancer Soc 2009, 115(7):1465-1471.

[4]. McKiernan J, Simmons R, Katz J, Russo P: Natural history of chronic renal insufficiency after partial and radical nephrectomy. Urology 2002, 59(6):816-820.

[5]. Gadzinski AJ, Roberts WW, Faerber GJ, Wolf JS, Jr.: Long-term outcomes of nephroureterectomy versus endoscopic management for upper tract urothelial carcinoma. J Urol 2010, 183(6):2148-2153. 
[6]. Roupret M, Hupertan V, Traxer O, Loison G, Chartier-Kastler E, Conort P, Bitker MO, Gattegno B, Richard F, Cussenot O: Comparison of open nephroureterectomy and ureteroscopic and percutaneous management of upper urinary tract transitional cell carcinoma. Urology 2006, 67(6):1181-1187.

[7]. Jung H, Giusti G, Fajkovic H, Herrmann T, Jones R, Straub M, Baard J, Osther PJS, Brehmer M: Consultation on UTUC, Stockholm 2018: aspects of treatment. World J Uro/ 2019, 37(11):2279-2287.

[8]. Smith AK, Stephenson AJ, Lane BR, Larson BT, Thomas AA, Gong MC, Jones JS, Campbell SC, Hansel $\mathrm{DE}$ : Inadequacy of biopsy for diagnosis of upper tract urothelial carcinoma: implications for conservative management. Urology 2011, 78(1):82-86.

[9]. Hasan MN, Roupret M, Keeley F, Cracco C, Jones R, Straub M, Traxer O, Osther PJS, Brehmer M: Consultation on UTUC, Stockholm 2018 aspects of risk stratification: long-term results and follow-up. World J Urol 2019, 37(11):2289-2296.

[10]. Margulis V, Shariat SF, Matin SF, Kamat AM, Zigeuner R, Kikuchi E, Lotan Y, Weizer A, Raman JD, Wood CG et al: Outcomes of radical nephroureterectomy: a series from the Upper Tract Urothelial Carcinoma Collaboration. Cancer-Am Cancer Soc 2009, 115(6):1224-1233.

[11]. Fernandez MI, Shariat SF, Margulis V, Bolenz C, Montorsi F, Suardi N, Remzi M, Wood CG, Roscigno $\mathrm{M}$, Kikuchi $\mathrm{E}$ et al: Evidence-based sex-related outcomes after radical nephroureterectomy for upper tract urothelial carcinoma: results of large multicenter study. Urology 2009, 73(1):142-146.

[12]. GL C, DH B: Ureteroscopic management of upper tract transitional cell carcinoma in patients with normal contralateral kidneys. The Journal of urology 2000, 164(4):1173-1176.

[13]. Soria F, Shariat SF, Lerner SP, Fritsche HM, Rink M, Kassouf W, Spiess PE, Lotan Y, Ye D, Fernandez MI et al: Epidemiology, diagnosis, preoperative evaluation and prognostic assessment of upper-tract urothelial carcinoma (UTUC). World J Urol 2017, 35(3):379-387.

[14]. Roupret M, Colin P, Yates DR: A new proposal to risk stratify urothelial carcinomas of the upper urinary tract (UTUCs) in a predefinitive treatment setting: low-risk versus high-risk UTUCs. Eur Uro/ 2014, 66(2):181-183.

[15]. Seisen T, Colin P, Roupret M: Risk-adapted strategy for the kidney-sparing management of upper tract tumours. Nat Rev Urol 2015, 12(3):155-166.

[16]. Simhan J, Smaldone MC, Egleston BL, Canter D, Sterious SN, Corcoran AT, Ginzburg S, Uzzo RG, Kutikov A: Nephron-sparing management vs radical nephroureterectomy for low- or moderate-grade, lowstage upper tract urothelial carcinoma. Bju Int 2014, 114(2):216-220.

[17]. Jeldres C, Lughezzani G, Sun M, Isbarn H, Shariat SF, Budaus L, Lattouf JB, Widmer H, Graefen M, Montorsi $\mathrm{F}$ et al: Segmental ureterectomy can safely be performed in patients with transitional cell carcinoma of the ureter. J Urol 2010, 183(4):1324-1329. 
[18]. Lughezzani G, Jeldres C, Isbarn H, Sun M, Shariat SF, Widmer H, Arjane P, Graefen M, Perrotte P, Montorsi $\mathrm{F}$ et al: Temporal stage and grade migration in surgically treated patients with upper tract urothelial carcinoma. Bju Int 2010, 105(6):799-804.

[19]. KS P, J S: When is partial ureterectomy acceptable for transitional-cell carcinoma of the ureter? J Endouro/ 2001, 15(4):405-408; discussion 409.

[20]. DS E, JW S, D L, DE P, ML B: Is nephroureterectomy necessary in all cases of upper tract transitional cell carcinoma? Long-term results of conservative endourologic management of upper tract transitional cell carcinoma in individuals with a normal contralateral kidney. Urology 2001, 58(2):174-178.

[21]. MC H, S W, AI S, T C, MD E, CG R: Prognostic factors, recurrence, and survival in transitional cell carcinoma of the upper urinary tract: a 30-year experience in 252 patients. Urology 1998, 52(4):594-601.

[22]. Leow J, Orsola A, Chang S, Bellmunt J: A contemporary review of management and prognostic factors of upper tract urothelial carcinoma. Cancer treatment reviews 2015, 41(4):310-319.

[23]. Li X, Cui M, Gu X, Fang D, Li H, Qin S, Yang K, Zhu T, Li X, Zhou L et al: Pattern and risk factors of local recurrence after nephroureterectomy for upper tract urothelial carcinoma. World J Surg Oncol 2020, 18(1):114.

[24]. Zhai T, Jin L, Feng L, Zhou Z, Liu X, Liu H, Ma W, Lu J, Chen W, Yao X et al: Perioperative Chemotherapy on Survival in Patients With Upper Urinary Tract Urothelial Carcinoma Undergoing Nephroureterectomy: A Population-Based Study. Front Oncol 2020, 10:481.

[25]. Kaag MG, O'Malley RL, O'Malley P, Godoy G, Chen M, Smaldone MC, Hrebinko RL, Raman JD, Bochner B, Dalbagni G et al: Changes in Renal Function Following Nephroureterectomy May Affect the Use of Perioperative Chemotherapy. Eur Urol 2010, 58(4):581-587.

[26]. Lane BR, Smith AK, Larson BT, Gong MC, Campbell SC, Raghavan D, Dreicer R, Hansel DE, Stephenson AJ: Chronic kidney disease after nephroureterectomy for upper tract urothelial carcinoma and implications for the administration of perioperative chemotherapy. Cancer-Am Cancer Soc 2010, 116(12):2967-2973.

[27]. Kang CH, Yu TJ, Hsieh HH, Yang JW, Shu K, Huang CC, Chiang PH, Shiue YL: The development of bladder tumors and contralateral upper urinary tract tumors after primary transitional cell carcinoma of the upper urinary tract. Cancer-Am Cancer Soc 2003, 98(8):1620-1626.

\section{Tables}


Table 1. Characteristics for UTUC patients stratified by surgical method.

\begin{tabular}{|c|c|c|c|c|c|}
\hline Characteristic & Total & No Surgery & $\frac{\text { NSS }}{1008}$ & RNU & P value \\
\hline Total & $\frac{10 .(10)}{10319}$ & $\frac{1 N 0 .(\%)}{963(9.3)}$ & $\frac{\text { No. (\%) }}{1273(123)}$ & $\frac{\text { NO. (\%) }}{8083(78.3)}$ & \\
\hline Age at diagnosis & & & & & $<0.001$ \\
\hline $18-50$ & $348(3.4)$ & $20(0.2)$ & $25(0.2)$ & $303(2.9)$ & \\
\hline $51-65$ & $2275(22.0)$ & $154(1.5)$ & $275(2.7)$ & 1846 (17.9) & \\
\hline $66-80$ & $5177(50.2)$ & $438(4.2)$ & 649 (6.3) & $4090(39.6)$ & \\
\hline$>80$ & $2519(24.4)$ & $351(3.4)$ & $324(3.1)$ & $1844(17.9)$ & \\
\hline Year of diagnosis & & & & & $<0.001$ \\
\hline 2004 & $840(8.1)$ & $70(0.7)$ & $118(1.1)$ & $652(6.3)$ & \\
\hline 2005 & $792(7.7)$ & $56(0.5)$ & $92(0.9)$ & $644(6.2)$ & \\
\hline 2006 & 895 (8.7) & $61(0.6)$ & $114(1.1)$ & $720(7.0)$ & \\
\hline 2007 & $869(8.4)$ & $66(0.6)$ & $116(1.1)$ & $687(6.7)$ & \\
\hline 2008 & 895 (8.7) & $84(0.8)$ & $128(1.2)$ & 683 6.6) & \\
\hline 2009 & $893(8.7)$ & $79(0.8)$ & $103(1.0)$ & $711(6.9)$ & \\
\hline 2010 & $882(8.5)$ & $75(0.7)$ & $114(1.1)$ & $693(6.7)$ & \\
\hline 2011 & $837(8.1)$ & $97(0.9)$ & $112(1.1)$ & $628(6.1)$ & \\
\hline 2012 & 787 (7.6) & $89(0.9)$ & $85(0.8)$ & $613(5.9)$ & \\
\hline 2013 & $830(8.0)$ & $81(0.8)$ & $91(0.9)$ & $658(6.4)$ & \\
\hline 2014 & $867(8.4)$ & $102(1.0)$ & $106(1.0)$ & $659(6.4)$ & \\
\hline 2015 & $932(9.0)$ & $103(1.0)$ & $94(0.9)$ & $735(7.1)$ & \\
\hline Sex & & & & & $<0.001$ \\
\hline Male & 6139 (59.5) & $543(5.3)$ & $843(8.2)$ & $4753(46.1)$ & \\
\hline Female & $4180(40.5)$ & $420(4.1)$ & $430(4.2)$ & $3330(32.3)$ & \\
\hline Race & & & & & 0.03 \\
\hline White & $9026(87.4)$ & $824(8.0)$ & $1103(10.7)$ & 7099 (68.8) & \\
\hline Black/Other & $1293(12.6)$ & $139(1.3)$ & $170(1.6)$ & $984(9.5)$ & \\
\hline Marital status & & & & & $<0.001$ \\
\hline Married & $6193(60.0)$ & $500(4.8)$ & $784(7.6)$ & $4909(47.6)$ & \\
\hline Unmarried & $3716(36.0)$ & $412(4.0)$ & $425(4.1)$ & $2879(27.9)$ & \\
\hline Unknown & $410(4.0)$ & $51(0.5)$ & $64(0.6)$ & $295(2.9)$ & \\
\hline Urban-rural residence & & & & & 0.604 \\
\hline Metropolitan & $9798(95.0)$ & $913(8.8)$ & $1214(11.8)$ & $7671(74.3)$ & \\
\hline Non-metropolitan & $521(5.1)$ & $50(0.5)$ & $59(0.6)$ & $412(4.0)$ & \\
\hline Insurance & & & & & 0.012 \\
\hline Yes & $7571(73.4)$ & $746(7.2)$ & $918(8.9)$ & $5907(57.2)$ & \\
\hline No & $88(0.9)$ & $8(0.1)$ & $6(0.1)$ & $74(0.7)$ & \\
\hline Unknown & $2660(25.8)$ & $209(2.0)$ & $349(3.4)$ & $2102(20.4)$ & \\
\hline Income & & & & & 0.491 \\
\hline Lower & $4303(41.7)$ & $421(4.1)$ & $520(5.0)$ & $3362(32.6)$ & \\
\hline Middle & $2906(28.2)$ & $258(2.5)$ & $350(3.4)$ & 2298 (22.3) & \\
\hline Upper & $3110(30.1)$ & $284(2.8)$ & 403 (3.9) & 2423 (23.5) & \\
\hline Summary stage & & & & & $<0.001$ \\
\hline Localized & 2732 (26.5) & $230(2.2)$ & $421(4.1)$ & $2081(20.2)$ & \\
\hline Regional & $6403(62.1)$ & $260(2.5)$ & $813(7.9)$ & $5330(51.7)$ & \\
\hline Distant & 1184 (11.5) & $473(4.6)$ & $39(0.4)$ & $672(6.5)$ & \\
\hline Grade & & & & & $<0.001$ \\
\hline I & $434(4.2)$ & $50(0.5)$ & $71(0.7)$ & $313(3.0)$ & \\
\hline
\end{tabular}




\begin{tabular}{cccccc} 
II & $1511(14.6)$ & $117(1.1)$ & $195(1.9)$ & $1199(11.6)$ & \\
III & $3135(30.4)$ & $386(3.7)$ & $387(3.8)$ & $2362(22.9)$ & \\
IV & $5239(50.8)$ & $410(4.0)$ & $620(6.0)$ & $4209(40.8)$ & \\
\hline AJCC Stage & & & & $<0.001$ \\
\hline I & $2976(28.8)$ & $253(2.5)$ & $444(4.3)$ & $2279(22.1)$ & \\
II & $1683(16.3)$ & $28(0.3)$ & $342(3.3)$ & $1313(12.7)$ & \\
III & $3143(30.5)$ & $41(0.4)$ & $339(3.3)$ & $2763(26.8)$ & \\
IV & $2517(24.4)$ & $641(6.2)$ & $148(1.4)$ & $1728(16.7)$ & \\
\hline Radiotherapy & & & & $<0.001$ \\
\hline Yes & $455(4.4)$ & $15(0.1)$ & $47(0.5)$ & $393(3.8)$ & \\
\hline No/Other & $9864(95.6)$ & $948(9.2)$ & $1226(11.9)$ & $7690(74.5)$ & \\
\hline Chemotherapy & & & & $<0.001$ \\
\hline Yes & $2164(21.0)$ & $381(3.7)$ & $208(2.0)$ & $1575(15.3)$ & \\
\hline No/Other & $8155(79.0)$ & $582(5.6)$ & $1065(10.3)$ & $6598(63.1)$ & \\
\hline
\end{tabular}


Table 2. Kaplan-Meier analysis overall survival and cancer-specific survival for UTUC patients.

\begin{tabular}{|c|c|c|c|c|c|c|}
\hline \multirow[b]{2}{*}{ Characteristic } & \multirow{2}{*}{$\begin{array}{c}\text { OS } \\
\text { MST } \\
\text { (months) }\end{array}$} & \multicolumn{2}{|c|}{ Kaplan-Meier } & \multirow{2}{*}{$\begin{array}{c}\text { CSS } \\
\text { MST } \\
\text { (months) }\end{array}$} & \multicolumn{2}{|c|}{ Kaplan-Meier } \\
\hline & & $\begin{array}{c}\text { Log Rank } \chi^{2} \\
\text { test }\end{array}$ & $\begin{array}{c}\mathrm{P} \\
\text { value }\end{array}$ & & $\begin{array}{c}\log \operatorname{Rank} \chi 2 \\
\text { test }\end{array}$ & $\begin{array}{c}\mathrm{P} \\
\text { value }\end{array}$ \\
\hline Age at diagnosis & & 720.68 & $\square 0.001$ & & 93.79 & $\square 0.001$ \\
\hline $18-50$ & 92.08 & & & 104.84 & & \\
\hline $51-65$ & 80.70 & & & 104.64 & & \\
\hline $66-80$ & 61.56 & & & 100.82 & & \\
\hline$>80$ & 37.74 & & & 87.31 & & \\
\hline Sex & & 0.90 & 0.344 & & 28.45 & $\square 0.001$ \\
\hline Male & 61.25 & & & 100.79 & & \\
\hline Female & 60.88 & & & 95.56 & & \\
\hline Race & & 1.89 & 0.169 & & 18.45 & $\square 0.001$ \\
\hline White & 61.32 & & & 100.32 & & \\
\hline Black/Other & 59.62 & & & 91.81 & & \\
\hline Marital status & & 71.99 & $\square 0.001$ & & 27.84 & $\square 0.001$ \\
\hline Married & 64.84 & & & 101.41 & & \\
\hline Unmarried & 54.75 & & & 94.85 & & \\
\hline Unknown & 60.53 & & & 101.02 & & \\
\hline $\begin{array}{l}\text { Urban-rural } \\
\text { residence }\end{array}$ & & 1.74 & 0.188 & & 3.66 & 0.160 \\
\hline Metropolitan & 61.24 & & & 99.25 & & \\
\hline Non-metropolitan & 58.31 & & & 98.68 & & \\
\hline Income & & 15.84 & $\square 0.001$ & & 12.21 & 0.002 \\
\hline Lower & 58.42 & & & 96.62 & & \\
\hline Middle & 62.68 & & & 100.51 & & \\
\hline Upper & 63.29 & & & 101.68 & & \\
\hline Summary stage & & 2854.23 & $\square 0.001$ & & 2853.40 & $\square 0.001$ \\
\hline Localized & 85.21 & & & 125.18 & & \\
\hline Regional & 58.84 & & & 97.00 & & \\
\hline Distant & 14.16 & & & 26.85 & & \\
\hline Grade & & 305.38 & $\square 0.001$ & & 271.73 & $\square 0.001$ \\
\hline $\mathrm{I}$ & 81.70 & & & 124.43 & & \\
\hline II & 82.63 & & & 119.98 & & \\
\hline III & 54.03 & & & 91.74 & & \\
\hline IV & 56.79 & & & 94.06 & & \\
\hline AJCC Stage & & 2468.48 & $\square 0.001$ & & 2478.87 & $\square 0.001$ \\
\hline I & 85.61 & & & 125.23 & & \\
\hline II & 72.92 & & & 115.23 & & \\
\hline III & 58.99 & & & 96.48 & & \\
\hline IV & 25.87 & & & 49.76 & & \\
\hline Radiotherapy & & 133.54 & $\square 0.001$ & & 161.07 & $\square 0.001$ \\
\hline Yes & 33.81 & & & 58.27 & & \\
\hline No & 62.34 & & & 100.94 & & \\
\hline Chemotherapy & & 98.78 & $\square 0.001$ & & 267.48 & $\square 0.001$ \\
\hline Yes & 50.37 & & & 76.85 & & \\
\hline No & 63.80 & & & 104.80 & & \\
\hline Surgery methods & & 1476.78 & $\square 0.001$ & & 1255.92 & $\square 0.001$ \\
\hline No & 17.66 & & & 40.04 & & \\
\hline NSS & 70.70 & & & 115.10 & & \\
\hline RNU & 64.65 & & & 102.07 & & \\
\hline
\end{tabular}


Abbreviations: OS: Overall Survival; CSS: Cancer Specific Survival; MST: Mean Survival Time; NSS: Nephron Sparing Surgery; RNU: Radical Nephroureterectomy. 
Table 3. Risk factors for survival: outcome is overall survival and cancerspecific survival.

Characteristic

\begin{tabular}{|c|c|c|c|c|c|c|c|}
\hline \multicolumn{2}{|c|}{$\begin{array}{c}\text { univariate COX } \\
\text { analysis }\end{array}$} & \multicolumn{2}{|c|}{$\begin{array}{c}\text { Multivariate Cox } \\
\text { analysis }\end{array}$} & \multicolumn{2}{|c|}{$\begin{array}{l}\text { univariate COX } \\
\text { analysis }\end{array}$} & \multicolumn{2}{|c|}{$\begin{array}{c}\text { Multivariate Cox } \\
\text { analysis }\end{array}$} \\
\hline $\begin{array}{l}\text { Hazard Ratio } \\
(95 \% \text { CI })\end{array}$ & $P$ value & $\begin{array}{c}\text { Hazard } \\
\text { Ratio (95\% } \\
\text { CI) }\end{array}$ & $P$ value & $\begin{array}{c}\text { Hazard } \\
\text { Ratio (95\% } \\
\text { CI) }\end{array}$ & $P$ value & $\begin{array}{c}\text { Hazard } \\
\text { Ratio } \\
(95 \% \text { CI) }\end{array}$ & $P$ value \\
\hline
\end{tabular}

Age at

diagnosis

\begin{tabular}{lllllllll}
$18-50$ & Reference & & Reference & & Reference & \multicolumn{3}{c}{ Reference } \\
$51-65$ & $1.36(1.13-$ & $<0.001$ & $1.33(1.11-$ & 0.003 & $1.03(0.82-$ & 0.810 & $1.03(0.82-$ & 0.815 \\
& $1.64)$ & & $1.60)$ & & $1.29)$ & & $1.29)$ & \\
$66-80$ & $2.04(1.71-$ & $<0.001$ & $1.96(1.64-$ & $<0.001$ & $3.88(3.65-$ & 0.200 & $1.16(0.93-$ & 0.192 \\
& $2.44)$ & & $2.35)$ & & $4.12)$ & & $1.44)$ \\
$>80$ & $3.43(2.87-$ & $<0.001$ & $3.16(2.63-$ & $<0.001$ & $5.98(5.57-$ & $<0.001$ & $1.64(1.31-$ & $<0.001$ \\
& $4.12)$ & & $3.79)$ & & $6.43)$ & & $2.06)$
\end{tabular}

Race

White

Reference

Reference

Reference

Black/Other $1.06(0.98-\quad 0.173$

1.14)

1.27 (1.14-

1.41)

$1.24(1.10-<0.001$

Marital status

Married

Reference

Reference

$\begin{array}{ll} & \text { Reference } \\ <0.001 & 1.23(1.13-\end{array}$

1.38)

Unmarried

1.26 (1.19-

$<0.001$

1.12 (1.06-

Reference

1.18)

1.33)

$1.07(0.93$

0.374

$1.04(0.90-$

1.19)

0.614

$0.91(0.73-$

1.14)

Urban-rural

1.23)

residence

\begin{tabular}{ccccccc} 
Metropolitan & Reference & & Reference & \multicolumn{3}{c}{ Reference } \\
Non- & $1.06(1.02-$ & 0.007 & $1.09(0.97-$ & 0.169 & $1.10(0.93-$ & 0.276 \\
metropolitan & $1.10)$ & & $1.22)$ & & $1.30)$ &
\end{tabular}

Income

Lower

Middle

Upper

Summary

stage

Localized

Distant

nal

Reference

$1.87(1.75-<0.001$

2.00)

Reference
$0.91(0.85$

$0.97)$

0.003

0.93 (0.87-
$0.99)$

0.017

Reference

0.88 (0.80-

$0.96)$

$0.90(0.84-<0.001$
$0.95)$

$0.90(0.84-$

$0.06)$

0.001

0.87 (0.79-

$0.95)$

0.006

Reference

$(0.82-$

$0.99)$

$1.23)$

$0.92(0.73-0.440$

1.14)

$0.86(0.78-\quad 0.001$ $0.94)$
Reference

0.69 (0.51-

$0.93)$

$1.36(0.99-$

1.86)

$<0.001$

Reference

0.84 (0.511.38)

1.75 (1.042.93)
0.488

0.035
Reference

3.06 (2.70-

$3.47)$

17.75

(15.43-

20.41)

Grade

\begin{tabular}{lcccccccc} 
I & Reference & & Reference & \multicolumn{3}{c}{ Reference } & \multicolumn{2}{c}{ Reference } \\
II & $5.14(4.24-$ & $<0.001$ & $0.95(0.81-$ & 0.510 & $1.45(1.05-$ & 0.022 & $1.28(0.93-$ & 0.133 \\
& $6.23)$ & & $1.11)$ & & $2.00)$ & $1.77)$ & \\
III & $10.25(8.44-$ & $<0.001$ & $1.29(1.11-$ & 0.001 & $3.90(2.89-$ & $<0.001$ & $2.04(1.51-$ & $<0.001$ \\
& $12.46)$ & & $1.49)$ & & $5.26)$ & $2.77)$ & \\
IV & $17.69(14.61-$ & $<0.001$ & $1.33(1.15-$ & $<0.001$ & $3.58(2.66-$ & $<0.001$ & $2.14(1.59-$ & $<0.001$ \\
& $21.42)$ & & $1.54)$ & & $4.82)$ & & $2.89)$
\end{tabular}

AJCC stage

I

II

III

$$
\text { 8.55) }
$$

0.015




\begin{tabular}{|c|c|c|c|c|c|c|c|c|}
\hline IV & $\begin{array}{l}4.84(4.50- \\
5.21)\end{array}$ & $<0.001$ & $\begin{array}{c}4.97(3.68- \\
6.71)\end{array}$ & $<0.001$ & $\begin{array}{c}10.39(9.16- \\
11.79)\end{array}$ & $<0.001$ & $\begin{array}{l}7.34(4.46- \\
12.10)\end{array}$ & $<0.001$ \\
\hline \multicolumn{9}{|l|}{ Surgery } \\
\hline No surgery & $\begin{array}{c}3.78(3.51- \\
4.08))\end{array}$ & $<0.001$ & $\begin{array}{c}2.94(2.71- \\
3.19)\end{array}$ & $<0.001$ & $\begin{array}{c}4.69(4.24- \\
5.19)\end{array}$ & $<0.001$ & $\begin{array}{c}3.02(2.70- \\
3.39)\end{array}$ & $<0.001$ \\
\hline NSS & $\begin{array}{c}0.86(0.79- \\
0.94)\end{array}$ & $<0.001$ & $\begin{array}{c}0.96(0.88- \\
1.04)\end{array}$ & 0.332 & $\begin{array}{c}0.62(0.54- \\
0.72)\end{array}$ & $<0.001$ & $\begin{array}{c}0.76(0.66- \\
0.88)\end{array}$ & $<0.001$ \\
\hline RNU & Reference & & Reference & & Reference & & Reference & \\
\hline \multicolumn{9}{|l|}{ Radiotherapy } \\
\hline Yes & Reference & & Reference & & Reference & & Reference & \\
\hline No & $\begin{array}{l}0.53(0.48- \\
0.60)\end{array}$ & $<0.001$ & $\begin{array}{c}0.70(0.63- \\
0.78)\end{array}$ & $<0.001$ & $\begin{array}{c}0.41(0.36- \\
047)\end{array}$ & $<0.001$ & $\begin{array}{c}0.67(0.58- \\
0.69)\end{array}$ & $<0.001$ \\
\hline \multicolumn{9}{|l|}{ Chemotherapy } \\
\hline Yes & Reference & & Reference & & Reference & & Reference & \\
\hline No & $\begin{array}{c}0.73 \\
(0.69 .0 .78)\end{array}$ & $<0.001$ & $\begin{array}{c}1.24(1.16- \\
1.33)\end{array}$ & $<0.001$ & $\begin{array}{c}0.51(0.46- \\
0.55)\end{array}$ & $<0.001$ & $\begin{array}{c}1.22(1.10- \\
1.34)\end{array}$ & $<0.001$ \\
\hline
\end{tabular}

Abbreviations: OS: Overall Survival; CSS: Cancer Specific Survival; MST: Mean Survival Time; NSS: Nephron Sparing Surgery; RNU: Radical Nephroureterectomy. 
Table 4. Subgroup analyses stratified by summary stage and grade for overall survival and cancerspecific survival.

\begin{tabular}{|c|c|c|c|c|c|c|}
\hline \multirow[b]{2}{*}{ Characteristic } & \multirow{2}{*}{$\begin{array}{c}\text { OS } \\
\text { MST } \\
\text { (months) }\end{array}$} & \multicolumn{2}{|l|}{ OS } & \multirow{2}{*}{$\begin{array}{c}\text { CSS } \\
\text { MST } \\
\text { (months) }\end{array}$} & \multicolumn{2}{|l|}{ CSS } \\
\hline & & $\begin{array}{c}\text { Hazard Ratio (95\% } \\
\text { CI) }\end{array}$ & $P$ value & & $\begin{array}{l}\text { Hazard Ratio } \\
(95 \% \mathrm{CI})\end{array}$ & Pvalue \\
\hline \multicolumn{7}{|l|}{ Grade I } \\
\hline No surgery & 28.23 & $4.28(2.91-6.29)$ & $<0.001$ & 74.77 & $3.17(1.38-7.28)$ & 0.006 \\
\hline NSS & 88.76 & $1.01(0.67-1.51)$ & 0.97 & 126.13 & $0.89(0.34-2.33)$ & 0.814 \\
\hline RNU & 90.59 & Reference & & 128.08 & Reference & \\
\hline \multicolumn{7}{|l|}{ Grade II } \\
\hline No surgery & 25.10 & $3.73(2.91-4.77)$ & $<0.001$ & 54.29 & $4.37(2.98-6.41)$ & $<0.001$ \\
\hline NSS & 84.76 & $1.04(0.83-1.30)$ & 0.748 & 130.43 & $0.66(0.39-1.10)$ & 0.111 \\
\hline RNU & 90.59 & Reference & & 128.08 & Reference & \\
\hline \multicolumn{7}{|l|}{ Grade III } \\
\hline No surgery & 15.00 & $2.60(2.28-2.97)$ & $<0.001$ & 32.87 & $2.73(2.28-3.27)$ & $<0.001$ \\
\hline NSS & 68.30 & $0.86(0.74-0.99)$ & 0.033 & 112.12 & $0.69(0.54-0.88)$ & 0.003 \\
\hline RNU & 90.59 & Reference & & 128.08 & Reference & \\
\hline \multicolumn{7}{|l|}{ Grade IV } \\
\hline No surgery & 16.66 & $2.91(2.57-3.29)$ & $<0.001$ & 36.02 & $3.02(2.56-3.56)$ & $<0.001$ \\
\hline NSS & 64.57 & $1.02(0.90-1.15)$ & 0.797 & 107.99 & $0.82(0.67-1.00)$ & 0.053 \\
\hline RNU & 90.59 & Reference & & 128.08 & Reference & \\
\hline \multicolumn{7}{|l|}{ Stage[ } \\
\hline No surgery & 31.24 & $3.41(2.88-4.04)$ & $<0.001$ & 73.17 & $4.99(3.73-6.69)$ & $<0.001$ \\
\hline NSS & 89.25 & $1.02(0.87-1.21)$ & 0.799 & 129.80 & $0.83(0.58-1.19)$ & 0.310 \\
\hline RNU & 90.59 & Reference & & 128.08 & Reference & \\
\hline \multicolumn{7}{|l|}{ Stage } \\
\hline No surgery & 34.22 & $2.94(1.97-4.61)$ & $<0.001$ & 60.52 & $4.69(2.46-8.95)$ & $<0.001$ \\
\hline NSS & 72.58 & $0.93(0.79-1.10)$ & 0.416 & 121.56 & $0.73(0.52-1.02)$ & 0.062 \\
\hline RNU & 90.59 & Reference & & 128.08 & Reference & \\
\hline \multicolumn{7}{|l|}{ Stage $\square$} \\
\hline No surgery & 19.53 & $2.96(2.13-4.12)$ & $<0.001$ & 44.17 & $2.65(1.58-4.44)$ & $<0.001$ \\
\hline NSS & 55.61 & $1.16(0.99-1.34)$ & 0.056 & 98.08 & $0.91(0.72-1.15)$ & 0.430 \\
\hline RNU & 90.59 & Reference & & 128.08 & Reference & \\
\hline \multicolumn{7}{|l|}{ Stage $\square$} \\
\hline No surgery & 11.39 & $1.81(1.62-2.01)$ & $<0.001$ & 22.16 & $2.02(0.49-0.86)$ & $<0.001$ \\
\hline NSS & 43.20 & $0.74(0.60-0.90)$ & 0.003 & 79.21 & $1.15(0.95-1.40)$ & 0.144 \\
\hline $\mathrm{RNU}$ & 90.59 & Reference & & 128.08 & Reference & \\
\hline
\end{tabular}

Abbreviations: OS: Overall Survival; CSS: Cancer Specific Survival; MST: Mean Survival Time; NSS: Nephron Sparing Surgery; RNU: Radical Nephroureterectomy.

\section{Figures}




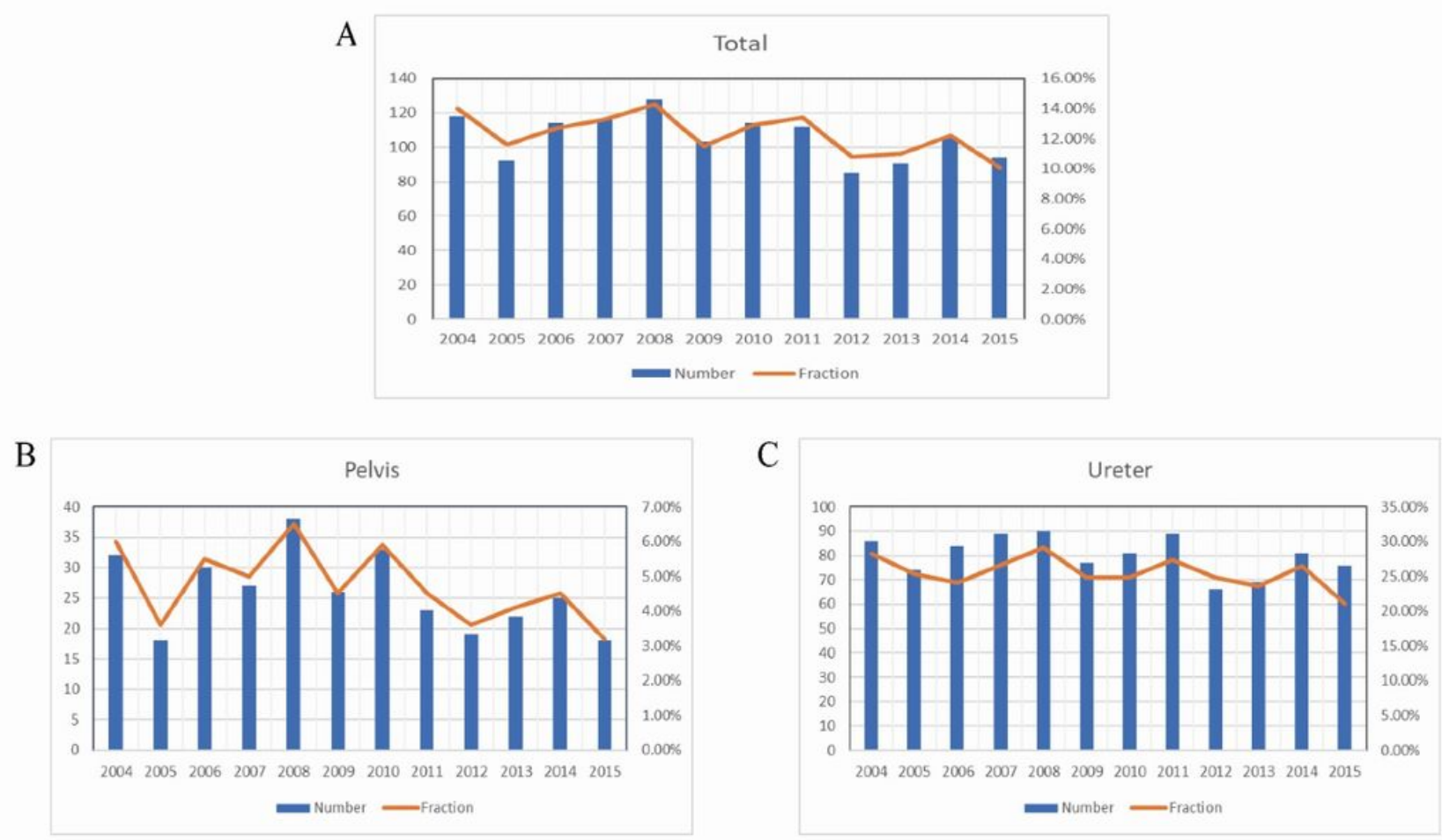

\section{Figure 1}

Trend of NSS rate from 2004 to 2015 stratified by tumor location. A show the distribution trend of all populations in different years. The population of Pelvis and Ureter was showed separately in B and C. 

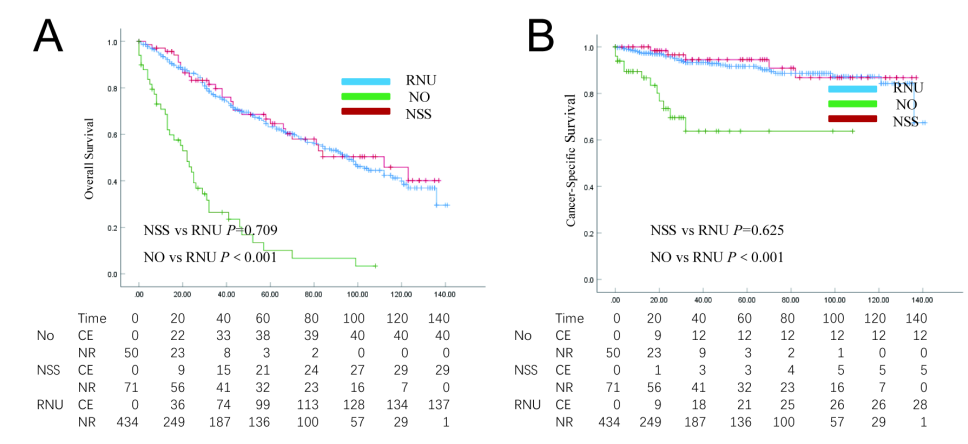

C

D

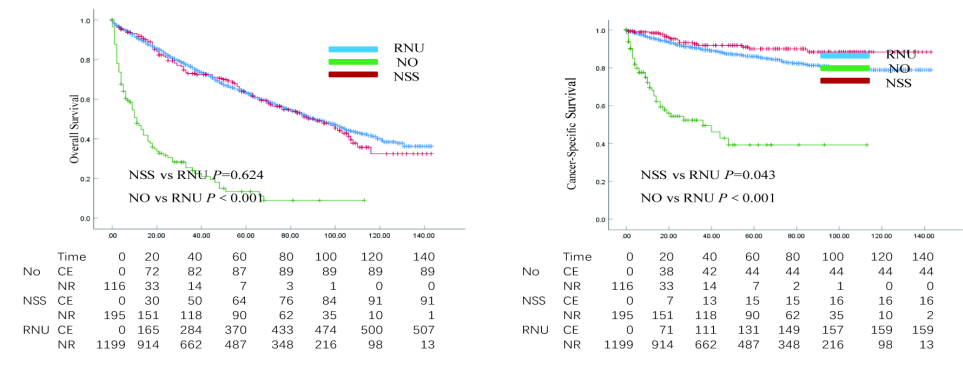

$\mathrm{E}$

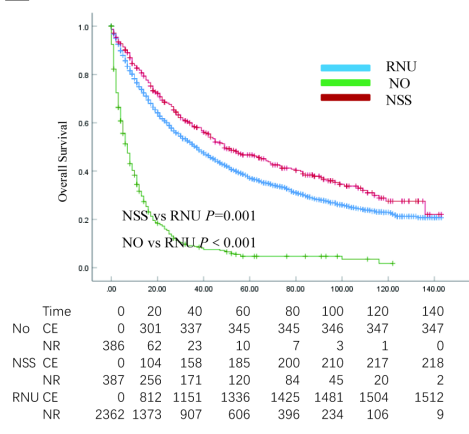

$\mathrm{F}$

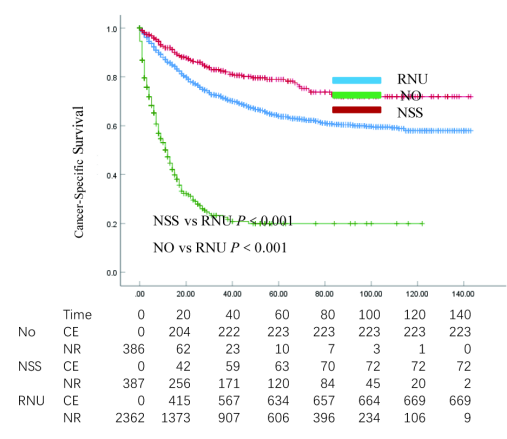

G

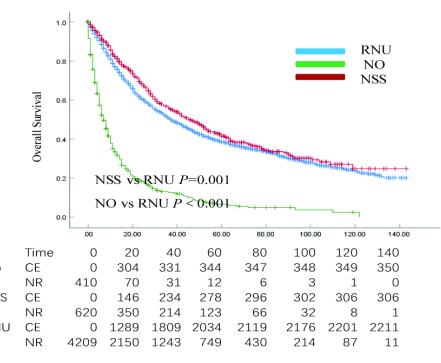

$\mathrm{H}$

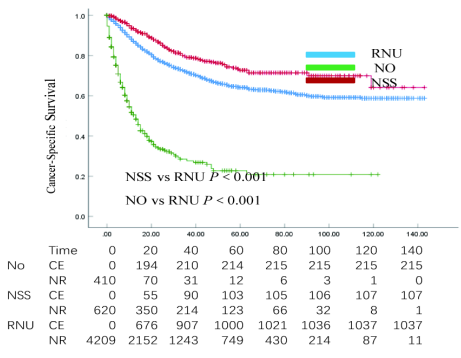

\section{Figure 2}

Overall survival and cancer-specific survival curves of UTUC patients according to surgical method in

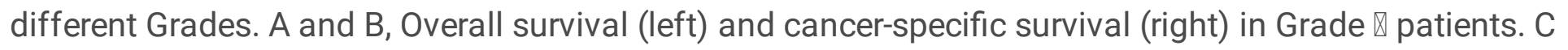
and D, Overall survival (left) and cancer-specific survival (right) in Grade $\otimes$ patients. E and F, Overall survival (left) and cancer-specific survival(right) in Grade $\otimes$ patients. $G$ and $H$, Overall survival (left) and cancer-specific survival (right) in Grade $\otimes$ patients. C.E, cumulative number of events; N.R, number at risk. 
A

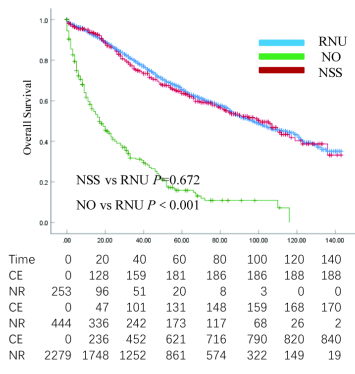

C

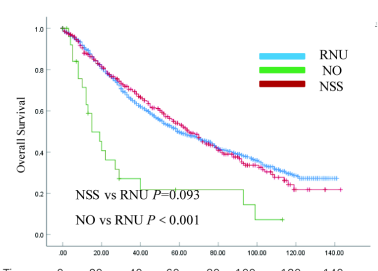

$\begin{array}{ccccccccc}\quad \text { Time } & 0 & 20 & 40 & 60 & 80 & 100 & 120 & 140 \\ \text { No } \mathrm{CE} & 0 & 14 & 18 & 18 & 18 & 20 & 20 & 20 \\ \mathrm{C} & 8 & 9 & 4 & 3 & 3 & 1\end{array}$

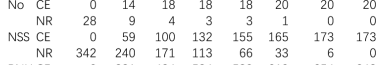

$\begin{array}{rrrrrrrrr}\text { NR } & 342 & 240 & 171 & 113 & 66 & 33 & 6 & 0 \\ \text { RNU CE } & 231 & 424 & 534 & 589 & 619 & 654 & 648 \\ \text { NR } & 1313 & 898 & 593 & 395 & 252 & 154 & 62 & 3\end{array}$

$\mathrm{E}$

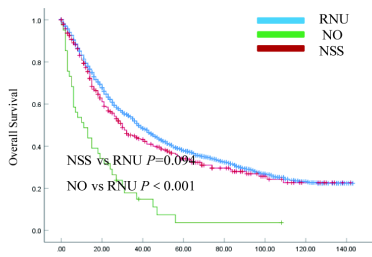

$\begin{array}{llrrrrrrrr} & \text { Time } & 0 & 20 & 40 & 60 & 80 & 100 & 120 & 140 \\ \text { No } & \mathrm{CE} & 0 & 28 & 34 & 37 & 37 & 37 & 37 & 37\end{array}$

\begin{tabular}{rrrrrrrrrr} 
NSS NR & 41 & 13 & 4 & 1 & 1 & 1 & 0 & 0 \\
\cline { 2 - 7 } & $\mathrm{CE}$ & 121 & 168 & 187 & 194 & 198 & 200 & 200 \\
& NR & 339 & 171 & 99 & 61 & 38 & 18 & 9 & 1
\end{tabular}

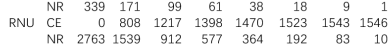

G

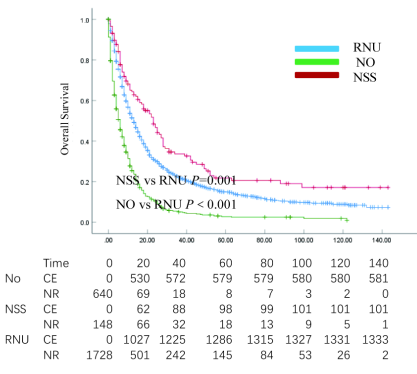

B

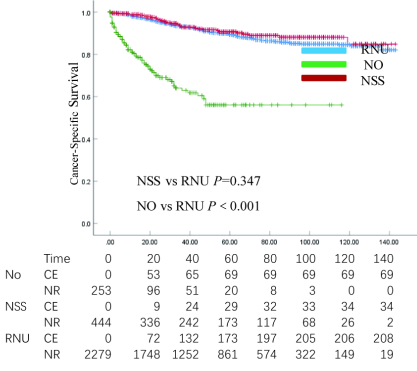

$\mathrm{D}$

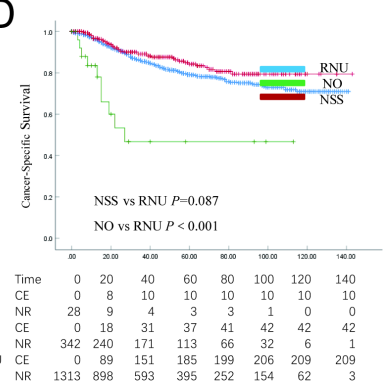

$\mathrm{F}$

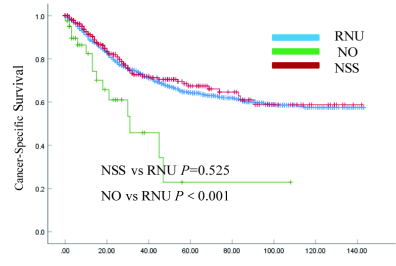

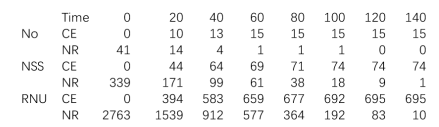

$\mathrm{H}$

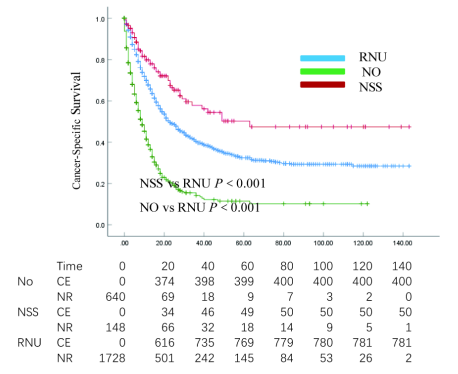

\section{Figure 3}

Overall survival and cancer-specific survival curves of UTUC patients according to surgical method in different Grades. A and B, Overall survival (left) and cancer-specific survival (right) in Stage \ patients. C and D, Overall survival (left) and cancer-specific survival (right) in Stage $\otimes$ patients. E and F, Overall survival (left) and cancer-specific survival (right) in Stage $\otimes$ patients. $G$ and H, Overall survival (left) and cancer-specific survival (right) in Stage $\otimes$ patients. C.E, cumulative number of events; N.R, number at risk. 


\section{Supplementary Files}

This is a list of supplementary files associated with this preprint. Click to download.

- Suplementalmaterials.docx 